\title{
Relevance of air-traffic controllers' tacit knowledge in enhancing air-traffic control and safety in Ghanaian airspace
}

\author{
Mohammed-Aminu Sanda \\ Department of Organization and Human Resource Management, \\ University of Ghana Business School, \\ P.O. Box LG 78, Legon, Accra, Ghana \\ and \\ Division of Human Work Science, \\ Department of Business Administration, \\ Technology and Social Sciences, \\ Luleå University of Technology \\ SE, 97187, Luleå, Sweden \\ Email: masanda@ug.edu.gh \\ Email:mohami@ltu.se
}

\begin{abstract}
This study explored the cognitive and workload demands of air-traffic control activity and the tacit knowledge used by air-traffic controllers to cope with the stress associated with such demands in ensuring air-traffic safety in Ghana. Guided by the systemic structural theory of activity, it was found that the air-traffic control activity entailed several challenges, whereby variety of tasks demand significant cognitive efforts, requiring use of tacit knowledge by the air-traffic controllers to augment their operational performances in order to enhance air-traffic safety. It is concluded that the functional efficiency and effectiveness of human work in the air-traffic control activity can be enhanced by understanding and integrating air-traffic controllers' tacit knowledge in the job design. By implication, this understanding can be incorporated in designing an operator-efficient and effective work system for air-traffic controllers in order to enhance management capacity of air-traffic safety in Ghana.
\end{abstract}

Keywords: air-traffic control activity; air-traffic controller; tacit knowledge; air-traffic safety; Ghana.

Reference to this paper should be made as follows: Sanda, M-A. (2018) 'Relevance of air-traffic controllers' tacit knowledge in enhancing air-traffic control and safety in Ghanaian airspace', Int. J. Human Factors Modelling and Simulation, Vol. 6, Nos. 2/3, pp.103-118.

Biographical notes: Mohammed-Aminu Sanda is an Adjunct Professor of Human Work Sciences at the Division of Human Work Science, Luleå University of Technology in Sweden, and a Senior Lecturer at the Department of Organization and Human Resource Management, University of Ghana Business School in Ghana, He received his PhD in Human Work Sciences from the Luleå University of Technology, Sweden in 2006, where he also worked as postdoctoral research fellow from January 2010 to December 2011. His research is on application of the systemic structural activity theory in creating knowledge on developing efficient work environments through the integration of organisational and human systems. 
This paper is a revised and expanded version of a paper entitled 'The emerging cognitive difficulties and emotional-motivational challenges of Ghanaian air traffic controllers: implication for improved job design' presented at the AHFE 2017 International Conference on Neuroergonomics and Cognitive Engineering, Los Angeles, California, USA, 17-21 July 2017.

\section{Introduction}

Air traffic control activity undertakers are generally considered as a group of workers who have to cope with highly demanding job situations. Earlier studies (Koros et al., 2003) have established that air-traffic control activity takes place in a complex environment. The job entails a complex set of routinised activities that require very high levels of knowledge and expertise, as well as practical application of specific cognitive skills pertaining communication and human relations. Blanken et al. (2010) indicated that the air-traffic control job involves cognitive demanding processes, such as constantly processing changing information, keeping the mental picture of the air traffic situation, dividing attention among different situations, solving conflicts, planning ahead, working under time pressure and constantly adapting to changing circumstances. Earlier studies (Ammennan et al., 1987) have categorised air traffic control activity into six main tasks as follows: situation monitoring, resolving aircraft conflicts, managing air traffic sequences, routing/planning flights, assessing weather impact, and managing sector/position resources. These main tasks have also been classified into about 46 sub-tasks which together entail up to 300 and 48 distinct operations (Ammennan et al., 1987). It is thus evident that the air-traffic control activity is characterised by high operator cognitive demand. Such high operator cognitive demand is desired to enable the air-controller cope with all the integrated air-traffic control operations at the radar workstations, which include spatial scanning, movement detection, image and pattern recognition, prioritising, visual and verbal filtering, coding and decoding, inductive and deductive reasoning, short-term and long-term memory, as well as mathematics and probabilistic reasoning.

The air-traffic control activity is centred on the use of radars to determine distances of airborne objects, mostly aircrafts, by measuring the time required for a radio signal to travel from a transmitter to the object and return. Such time measures are converted into 'lines of position' which are circles whose radius equate to the distance of the object under reference. Aside their uses to measure the distance airborne objects, radars are also used to measure the bearings of such objects through their directional antennas. Yet, the accuracy of such measure is deemed to be affected by the radar's design. Costa (1996) argues that the doubtfulness on the accuracy of radars' measure of airborne objects result in situations whereby air-traffic control activity undertakers find themselves entangled in judgement scenarios that can culminate into critical accidents, such as air-accidents, near-collisions or loss of control due to overload. Such judgement scenarios most often lead to the arousal of strong emotional reaction among air-traffic control activity undertakers (Costa, 1996) and its accompanying stress. This observation affirms Smith (1980) identification of the operative aspects of air-traffic control activity and its accompanying organisational structure as the main sources of stress reported by air-traffic controllers. Smith (1980) found that the stress associated with the operative 
aspect of the air-traffic control job emanate when the air-traffic load is at its peaks and operators are faced with time pressure, and also in situations which calls for operators to use their cognitive capabilities to offset equipment limitations and ensure operational safety. Folkard and Monk (1991) have observed that the performance of an air-traffic controller can be impaired by excessive workload at certain hours of the day, and a decline in mental and physical functions during the night.

In Ghana, the Kotoka International Airport is the main international airport serving both international and local flights, and as such has to contend with a significant traffic in its air-space. For the air-traffic controllers, the high traffic volume and resulting frequency congestion are factors that add to the complexity of their tasks. Thus the air-traffic control activity is characterised by un-planned task demands, and for which air-traffic controllers have to respond. These include the need to dynamically re-plan in response to weather changes, traffic management initiatives, airport construction, maintenance activities, and other associated air-traffic control activities. As such, the number of decisions required of air-traffic controllers is very enormous and highly stressful, especially when the controllers' decision-making capacity is stretched to the maximum. Therefore, in handling the high air-traffic volume and ensuring the safety of the airspace, the air-traffic controllers, who are responsible for managing the movement of aircrafts, are subjected to high mental demand within the work environment. It is thus important to uncover and understand the tacit knowledge they incorporate in their activity to ensure air space safety when working under situations of high mental demand. This importance is underlined by the argumentation that, even though automated systems must have the capacity to support a high situation awareness that stimulates good performance, it must not create automation bias, in terms of an over-reliance on decision support from the computerised system, but must provide reliable operator feedback to prevent possible mistakes (Sanda et al., 2014). Thus for the air-traffic control activity, there is the need for the development of knowledge to facilitate the integration of technological, organisational and human systems to help enhance the operational safety, effectiveness and efficiency of air-traffic management. This study, therefore, explored the perceived increase in the cognitive workload of air traffic controllers at Kotoka International Airport in Ghana, and the added-tacit knowledge they use in the performances of their air-traffic control activities that enable them to effectively manage and enhance air-traffic safety in Ghana's airspace.

\section{Literature review}

Technology usage in organisations is for the purposing of accomplishing work activities effectively and efficiently (Sanda et al., 2014). Based on this perspective, technologies are deemed to affect the social relations between themselves and their operators in organisations (Sanda et al., 2014). The technological effect on social relations is influenced by the technology's capacity to structure transactions between roles in an organisation's activity system (Aldrich, 2008). Aldrich (2008) viewed an activity system to consist of a bounded set of interdependent behaviours, with the nature of the interdependencies contingent upon technology's form. Air-traffic control is a work activity performed in teams that consist of air-traffic controllers, their supervisors and assistants, and associated workers from interrelated departments and units, including 
aircraft pilots. According to International Civil Aviation Organization (ICAO), the rapid and continued growth in air traffic globally is outpacing and putting strain on air-traffic control systems to handle the traffic volume and its inherent complexity. Koros et al. (2003) have characterised the complexity as influenced by unplanned demands, and the need to dynamically re-plan in response to weather changes, traffic management initiatives, airport construction, maintenance activities, and other events. Such unplanned tasks add to the difficulties air-traffic controllers encounter, and which can have dire consequences on air safety, because controllers might not have expected their occurrence, but, yet still, have to contain them as they occur, the consequence being increases in the controllers' workloads (Koros et al., 2003).

The leading factors that influence the complexity are high traffic volume and frequency congestion (Koros et al., 2003). Blanken et al. (2010) have noted that due to changes in the strategic traffic situation, working positions are combined or separated, resulting in changes in team configuration and operating procedures. The procedures describe the formal operating procedures within which air traffic has to be handled, and is comprised of the standard operating procedures and rules for conducting air traffic control activity, as well as its associated work-methods (Blanken et al., 2010). The changes in the strategic traffic situation can have consequences on the established procedures, in terms of increasing the complexity of the air-traffic control activity. In this regard, Blanken et al. (2010) argued that since the complexity of the air-traffic control activity is influenced by the pattern of the strategic traffic situation, which can be temporal or permanent, the physical framework within which air traffic has to be controlled is set by the strategic traffic situation. As such, the strategic traffic situation can vary, in terms of, airspace structure and sectors, airport layout and runways used, traffic volume and density, as well as flight planning and flow management (Blanken et al., 2010). The tactical traffic situation comprises the actual traffic situation, the aircraft positions and clearances given, the mix in traffic and aircraft performances, the traffic flows and routings, the actual weather situation and emergencies and exceptional situations (Blanken et al., 2010). The air-traffic control activity is thus, characterised by the dynamic nature of the air-traffic volume, with continuous changes in the information and situation, often resulting in unexpected scenarios that can be cognitively demanding (Blanken et al., 2010).

The ICAO (2002) has noted that the rapid growth in air traffic has increased workload of air-traffic controllers, thereby requiring them to have cognitive skills that can enable them to effectively and efficiently enhance air-traffic safety when engaged in their air-traffic control activities. According to ICAO (2002), air traffic control requires a lot of cognitive processing in the synthesis and analysis of significant amounts of information, the mastery of complex procedures, real time problem solving, and the listening and speaking skills necessary for effective information transfer. Pawlak et al. (1996) found cognitive complexity to be influenced by the number of procedures used, the complexity of procedures, and diversity in the work methods. Air-traffic controllers use several systems in performing their tasks. These include communication systems, planning systems, and navigation and surveillance systems. Established procedures for the air-traffic control include; communicating multiple or lengthy instructions to every aircraft within the precinct of the covered airspace (Blanken et al., 2010). Thus, the cognitive skills air-traffic controllers are expected to acquire (ICAO, 2002) includes: 
1 Perception for sensing and reacting to visual and aural information. For example, detecting and resolving deviations from planned flight paths.

2 Being attentive/vigilante for prolonged periods of intense activity, and sometimes for prolonged periods of relative inactivity.

3 Learning to master the procedures, practices and peculiarities of the position as well as from day to day operational experience.

4 Memory to interpret evolving situations correctly and quickly.

That is, memory for dealing with situations in real time, and for integrating knowledge and procedures (ICAO, 2002). Additional cognitive skills (ICAO, 2002) required of air-traffic controllers include:

1 Information processing to synthesise many diverse pieces of changing data about traffic, weather, aerodrome conditions, and navigation-aids into a coherent picture and to manage that picture in accordance with existing plans and procedures.

2 Situational awareness to successfully integrate all relevant information into a coherent and current picture. This, according to ICAO (2002), includes knowledge of the present, past and pending situation, system functioning, human roles and tasks, as well as air traffic controllers roles, procedures and losing this 'picture' is the worst nightmare for air traffic controllers.

3 planning to integrate the time element by extrapolating from the controller's picture to develop expected aircraft sequencing and spacing in accordance with established procedures and objectives

4 Communicating for both the reception and correct interpretation of information as well as for sending information and instructions, often through the barriers of language and radio noise.

According to ICAO (2002), effective communication also requires a feedback mechanism to confirm understanding. For example, pilots have to read back the instructions given by controllers and controllers must listen to the read back. The remaining cognitive skills (ICAO, 2002) requirement for air-traffic controllers are:

1 Problem-solving abilities to resolve deviations from plans and cope with unforeseen circumstances such as system outages or aircraft emergencies.

2 Decision-making abilities for the timely selection of the best alternative course of action for a particular situation, and appreciating how such decision will affect subsequent traffic.

According to ICAO (2002), traffic must not only flow safely and expeditiously, it must continue to be orderly.

The acquisition of all the cognitive skills outlined above implies the formal provision of cognitive identify to the air-traffic controllers. Abrahamsson and Johansson (2008) have noted that the creation of work identity involves learning. Abrahamsson and Johansson (2008) explained that individuals need to figure out what identities to enact, how to enact them and how others perceive their identity. In this regard, there is the tendency that individuals' actions and identity formation at work will be affected by the 
organisational structures and/or the symbols that characterised work activity (Sanda et al., 2011). This, from the perspectives of Wenger (1998), can be understood as both socialisation and learning entailed in the process of becoming a full member of an organisation or a community of practice. Arguing from the perspectives of Fenwick (2006), the operators' awareness of their tacit knowledge and utilising it to enhance the goal-attainment of their object-oriented activities form a critical element of their identity. Such tacit knowledge, classified Acker (2006) as a critical element in practice evolution that merges with three other organisational elements to form four organisational processes that influence employees' identity. The three organisational elements outlined by Acker (2006) include, the more formal structural aspects of the workplace (i.e., technology, organisational structure and qualification demands), the identity aspects of work, the symbolic aspects of work (i.e., stories, myths, ideas and perceptions of what a 'real' worker is like), and relations at the workplace. In this regard, workers engaged in organisational activity are can be viewed as entities needing new mental images of themselves in order to be able to relate positively to their work environment (Sanda et al, 2011). Based on this perspective, Sanda et al (2011) noted that the work environment must also have a work organisation process professed by good working and social conditions that enhances workers' object-oriented and subject-oriented activities, and supports high productivity. Sanda et al. (2011) argued that when workers use technologies to accomplish work, both their object-oriented and subject-oriented activities are influenced by the work system. Hendrick and Kleiner (2001) have identified technology as the source of such influence. In the course of their usage in work processes, technologies structure the transaction of workers' roles in the organisation, thereby affecting the social relation between it (technology) and the worker.

\section{Methodology}

Various researchers (Mirabella and Wheaton, 1974; Venda, 1975) have attempted to develop suitable methods for task complexity evaluation, including the use of various units of measure, such as the number of controls and indicators, or the number of actions. Regarding studies on workload in air traffic control, many were conducted in the laboratory. Bourne and Yaroush (2003) have noted that the laboratory studies were relatively focused on weak acute stress. Experiments regarding workload in air navigation were also performed under very simplified simulated conditions, often far from the reality (Villena et al., 2008). In the experiments, controllers were exposed to simulated stressful events that were not necessarily the true reflection of the actual events (Villena et al., 2008). Principally, because the aforementioned methods employed incommensurable units of measure, they cannot be used to successfully evaluate task complexity (Bedny and Karwowski, 2007; Sanda, 2016). According to Bedny and Karwowski (2007), the quantitative method of task complexity evaluation suggests a requirement for units of measurement and measurement procedures that permit the comparison of different elements of activity. Since this important issue has not yet been resolved, task complexity can be evaluated both experimentally and theoretically (Bedny and Karwowski, 2007). The experimental evaluation is based on criteria, such as the evaluation of probability of errors, the measurement of time performance, the evaluation of duration of skill acquisition, and the measurement of mental fatigue (Bedny and 
Karwowski, 2007). In such evaluation, expert judgments, such as the use of a five-point scale for complexity evaluation, and the subjective opinion of the task performer can also be taken into consideration (Bedny and Karwowski, 2007; Kieras and Polson, 1985). It has been pointed out by both Bedny and Karwowski (2007) and Patton (1990) that the motivational aspects of operators' activities are usually ignored in the operator-job design process. Yet, these functional blocks of self-regulation are connected with the evaluation of task difficulty and task significance, and thus play a central role in integrating the cognitive and motivational aspects of an operator's activity (Bedny and Karwowski, 2007; Sanda, 2016). Thus for the air traffic controllers, the fundamental notions of task complexity and cognitive challenge and significance in the air-traffic control activity, and the concentration of attention on the conduct of the Air-traffic controller will permit a researcher to take into consideration, not only the cognitive and behavioural aspects of the activity, but also its motivational aspects (Bedny and Karwowski, 2007; Sanda, 2016). In this regard, the subjective opinions of the air-traffic controllers (task performers) were taken into consideration (Sanda, 2016).

\subsection{Data collection method}

Due to the limited number of air traffic controllers in Ghana, and the difficulty of having access to them, the snowballing technique (Patton, 1990; Sanda, 2010) was used to get as many air-traffic controllers to complete the questionnaires as possible. In all, out of a total 85 air-traffic controllers at the Kotoka International Airport, 50 volunteered to participate in the study. A standardised self-completion questionnaire entailing five sections was used to collect quantified qualitative data from the 50 study participants. Section A of the questionnaire collected information on the controllers' demography. Section B of the questionnaire collected information on the controllers' measure of their work stress. Section C of the questionnaire collected information on the controllers' measure of their workload. Section D of the questionnaire collected information on the controllers' measure of their works' cognitive demand.

Since the study participants' responses were a representation of their subjective opinions (i.e., expert judgments) on the complexity of the air-traffic control activity they perform, it was deemed appropriate to use a five-point scale for such complexity evaluation (Bedny and Karwowski, 2007; Sanda, 2016). As such, the response ratings in the questionnaire ranged from 1 (very low) to 5 (very high). In the data collection process, 50 questionnaires were delivered to the management of the air-traffic control unit at the Kotoka International Airport in Accra. The management then facilitated the administering of the questionnaire to the 50 study participants identified from the snowballing exercise. All the 50 questionnaires administered were fully completed and returned.

\subsection{Data analysis procedure}

The systemic analytical approach (Bedny and Karwowski, 2007) was used. The cognitive aspect of complexity that depended on the specificity of workload and stress in the air-traffic controllers' activities, and the emotional-motivational aspects of complexity that reflected the energetic aspects of the air-traffic control activity were analysed descriptively. 


\section{Results analyses}

\subsection{Demographic assessment of study participants}

The gender distribution of the respondents showed that males dominate the air-traffic control activity at the airport. In all there were more male respondents (80\%) than female respondents (20\%). Regarding the study participants' years of experience in the air-traffic control activity, in terms of the number of years spent engaged in the activity (see Figure 1), 38 (76\%) of the study participants were quite experienced, having been in practice for periods of four years and above. Ten (20\%) of them have been in practice for less than one year. Of the two remaining two participants, one had two years work experience while the other had four year experiences. This distribution showed that majority of the study participants had vast experience in air-traffic control activity.

Figure 1 Distribution of study participants' years of experience as air-traffic controllers (see online version for colours)

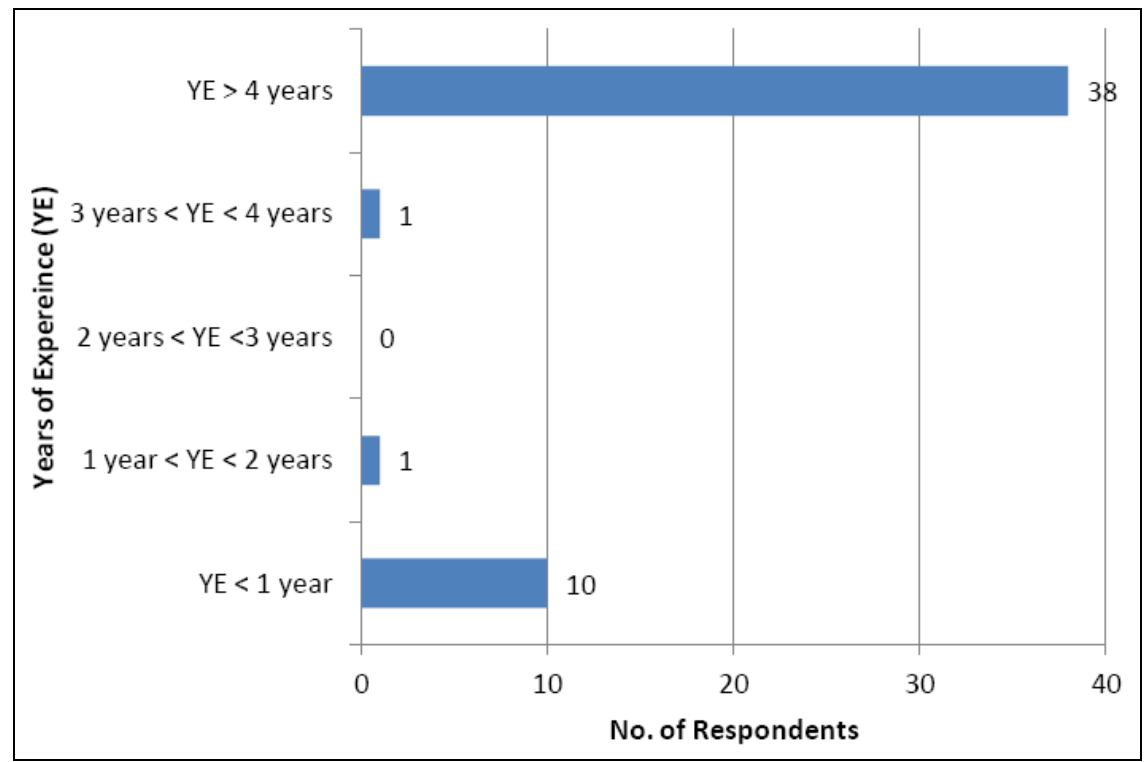

The implication of the demographic distribution is that, majority of the air-traffic controllers (i.e., study participants) surveyed were duly qualified and experienced to provide the needed information requested in the psychometric tool (questionnaire) employed.

\subsection{Assessment of cognitive demand on air-traffic controllers}

The distribution of study participants' perspectives on the cognitive demand of the air-traffic control activity, and with which they have to cope in order to ensure air-traffic space is shown in Figure 2. 
Figure 2 Study participants' perspectives on the cognitive demand of tasks in air-traffic control activity (see online version for colours)

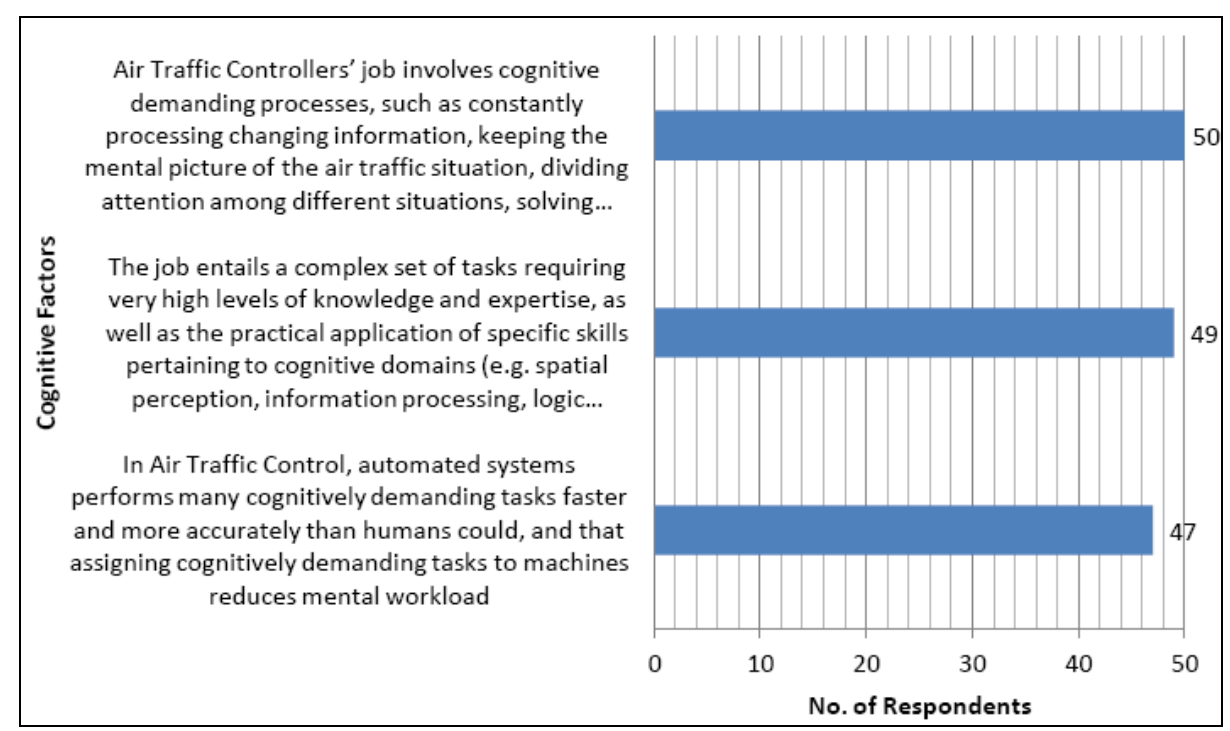

As it is highlighted in Figure 2, all the 50 study participants agree that the air-traffic control activity involves cognitive demanding processes, such as constantly processing changing information, keeping the mental picture of the air-traffic situation, dividing attention among different situations, solving conflicts, planning ahead, working under time pressure and constantly adapting to changing circumstances is confirmed. All the participants shared the view incorporation of all the tasks in the air-traffic control activity performance adds to its complexity and cognitive demand. Forty seven (90\%) of the study participants agreed that in the air-traffic control activity, automated systems performs many cognitively demanding tasks faster and more accurately than humans could, and that assigning cognitively demanding tasks to machines is expected to reduces their mental workload. Despite this notion, they viewed that assigning them cognitively demanding tasks increases their mental workload. Almost all the study participants (98\%) shared the perception that the air-traffic control activity entails a complex set of tasks requiring very high levels of knowledge and expertise, as well as the practical application of specific skills pertaining to cognitive domains (e.g., spatial perception, information processing, logic reasoning, decision making), communicative aspects and human relations. The participant agreed that working towards meeting all these task demands add to the complexity of their jobs as air-traffic controllers, and the excessive cognitive demand it requires of them towards ensuring the air-space safety.

\subsection{Assessment of mental workload demand on air-traffic controllers}

The distribution of study participants' perspectives on the mental workload characteristics of the air-traffic control activity, and with which they have to cope in order to ensure air-traffic space is shown in Figure 3. 
Figure 3 Study participants' perspectives on the mental workload characteristics of tasks in air-traffic control activity (see online version for colours)

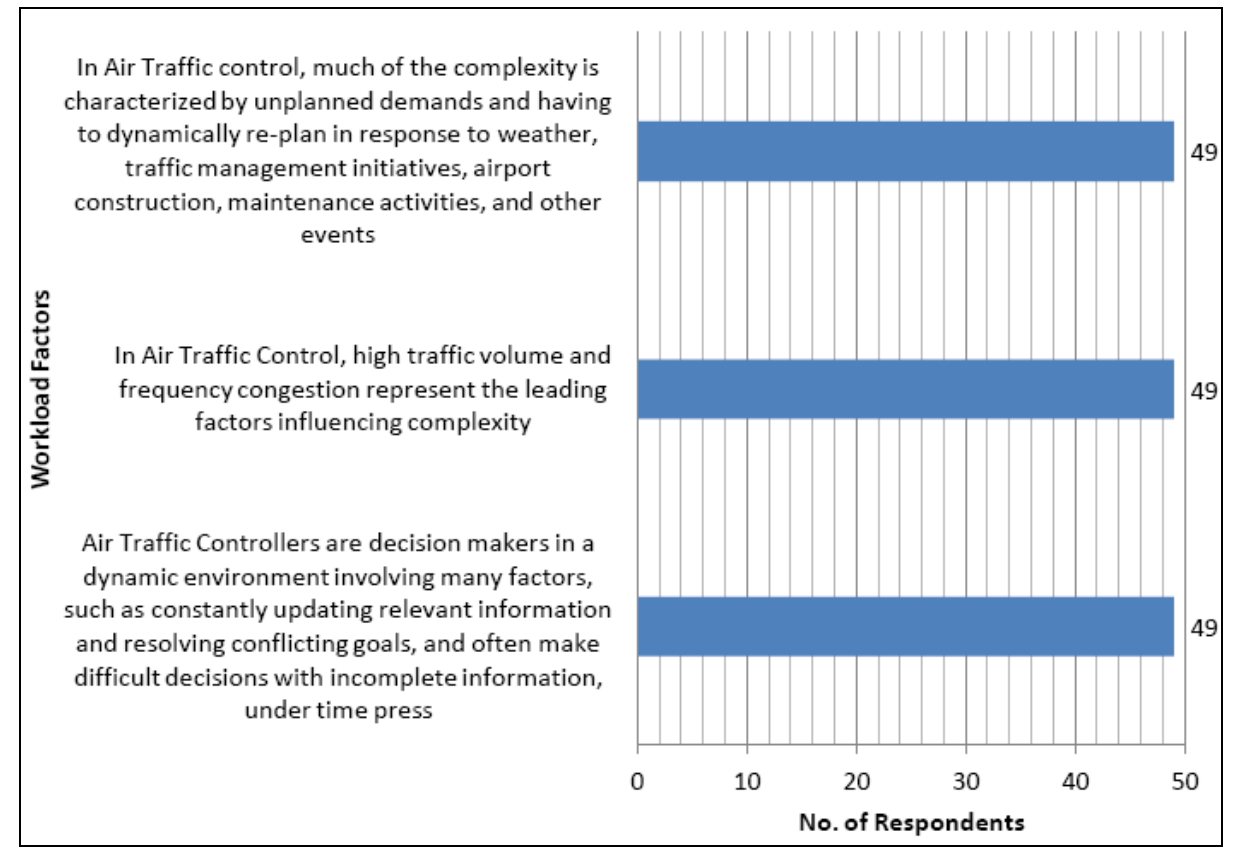

As it is shown in Figure 3, 49 (98\%) of the study participants shared the perception that the air-traffic control activity entails high traffic volume and frequency congestion, which situations adds to the complexity of the activity. In this respect they all agreed that much of the complexity in the air-traffic control activity, and its accompanying workload demand is characterised by unplanned demands and having to dynamically re-plan in response to weather, traffic management initiatives, airport construction, and maintenance activities. They agreed that incorporation of all these tasks in the activity performance adds to its complexity and cognitive demand. Similarly, almost all the study participants (98\%) agreed that in the air-traffic control activity, decisions are made in a dynamic environment involving many factors, such as constantly updating relevant information and resolving conflicting goals, and often making difficult decisions with incomplete information, under time pressure, and with high workload. The participants agreed that all these factors contribute in increasing their mental workload.

\subsection{Assessment of the stressfulness of air-traffic controllers' activities}

The distribution of study participants' perspectives on the stressfulness of the air-traffic controllers' activities, and with which they have to cope in order to ensure air-traffic space is shown in Figure 4.

As it is highlighted in Figure 4, 49 (98\%) of the study participants agree that the air-traffic control activity is a very stressful and demanding job. Almost all the participants (96\%) shared the view that the air-traffic control activity usually becomes stressful when the decision-making capacities of air-traffic controllers are stretched to the maximum. Similarly, almost all the study participants (96\%) agreed that in the 
performance of the air-traffic control activity, handling the information content of radio transmissions (e.g., instruction, information, question, report, and inquiry), their frequency and duration by air-traffic controllers add to the stress characteristics of their jobs.

Figure 4 Study participants' perspectives on the stressfulness of the air-traffic control activity (see online version for colours)

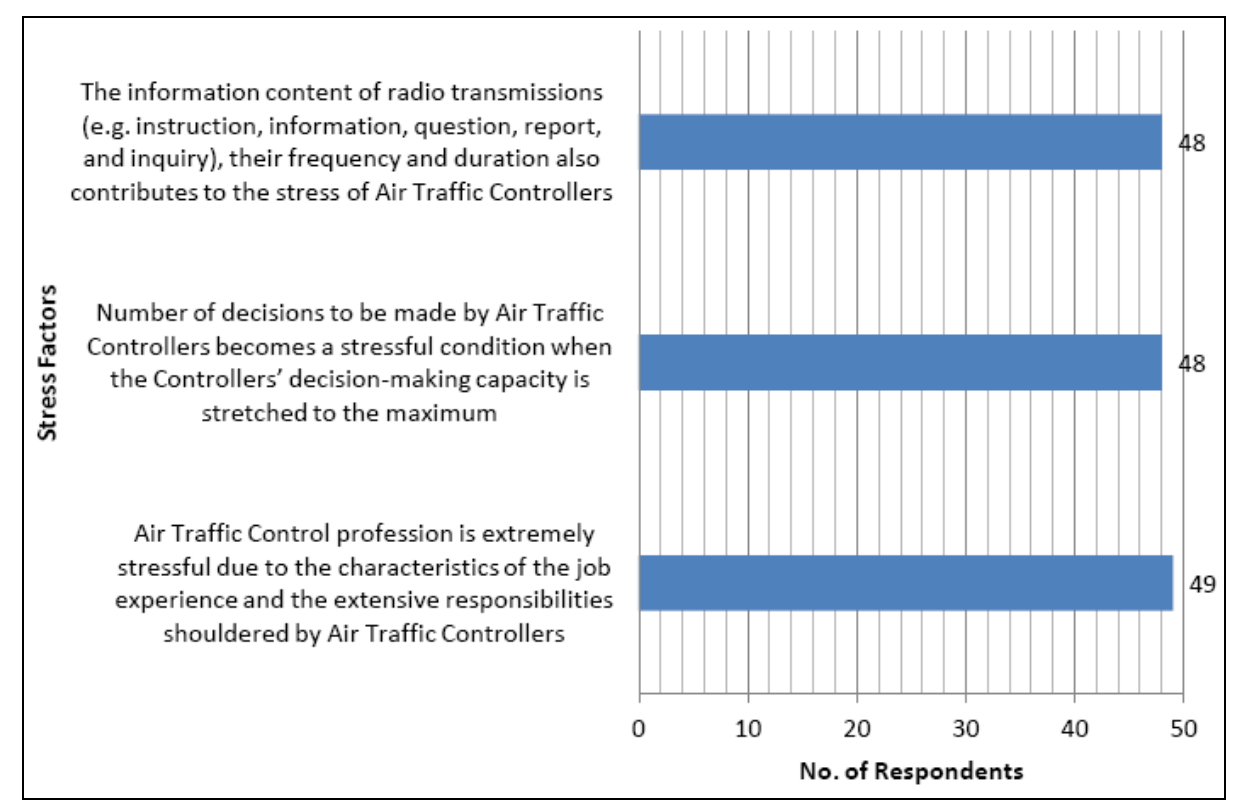

\section{Discussion}

The analyses above have shown that in the air-traffic control activity, the principal actor is the air-traffic controller who is simultaneously confronted with the challenges of handling the complex consequence of the air-traffic control activity, mostly manifested as cognitive and mental workload derivatives with their consequential stressful implications air-traffic controllers. In the air-traffic control activity, one task type is the engagement of air-traffic controllers in a complex set of tasks requiring very high levels of knowledge and expertise, as well as the practical application of specific skills pertaining to cognitive domains (e.g., spatial perception, information processing, logic reasoning, decision making), communicative aspects and human relations. From the results above, an other task, which occurs simultaneously with the physical task, is the air-traffic controllers' engagement in operations requiring significant cognitive input by interacting with digitised communication models. Such operations include the air-traffic controller constantly processing changing information, keeping the mental picture of the air-traffic situation, dividing attention among different situations, solving conflicts, planning ahead, working under time pressure, and constantly adapting to changing circumstances. Following the argumentation by Sanda (2016), the routinised operation in the air-traffic control activity can be said to entail several modes of decision-making, and as such 
signifies an important factor that influences the complexity of the task, and for which the coping strategy used by the task performers in order to compromise air-traffic safety standards needs to be understood in the job design process. Therefore, the increase in the cognitive aspect of complexity in air-traffic controllers' could be related to the need for them to alter the stereotypical actions of the designed tasks in the air-traffic control activity. The realisation here, using Bedny and Karwowski's (2007) argumentation as a point of departure, is that, while the decision-making process is more complicated when it is determined by information extracted from memory, it becomes easier to perform when it is predominantly determined by external stimuli or by information provided from external source. This therefore, implies that air-traffic controllers' objective and subjective activities are interdependent and shaped by their mechanisms of self-regulation.

The cognitive aspect of complexity in the air-traffic control activity is found to depend on the number of task elements and the specification of interactions of the different task elements. The task elements include, decision-making in a dynamic environment involving many factors, such as constantly updating relevant information and resolving conflicting goals, and often making difficult decisions with incomplete information, under time pressure, and with high workload. It also include, the handling of information content from radio transmissions (e.g., instruction, information, question, report, and inquiry), their frequencies and duration, a task is very stressful and demanding, and which stretches the controllers' decision-making capacity to the maximum. Thus, the complexity in the air-traffic control activity can be said to be defined by the number of static and dynamic components of the task and interaction among these components (Bedny and Karwowski, 2007; Sanda, 2016). In this regard, it is argued that the excessive cognitive requirement of the air-traffic control activity (as an object-oriented activity) influences the air-traffic controllers' expected goals of managing the air-traffic environment and ensuring air-space safety. As highlighted in the results, the air-traffic environment is inundated by high aircraft traffic volume and frequency congestion, air-traffic management initiatives (such as, aircraft landing and take-off movements, which are characterised by unplanned demands, with air-traffic controllers having to dynamically re-plan in response to changing weather situations), as well as airport construction and maintenance activities. Thus, arguing from the perspectives of Kieras and Polson (1985) and Sanda (2016), the number of operations in the air-traffic control activity that air-traffic controllers have to cope with (both planned and unpredicted evolved ones) must serve as the major criterion of determining the complexity of the air-traffic control activity, in terms of the level of cognitive and mental workload requirements and the stressfulness associated with their realisation. Therefore, the specificity of cognitive and mental workload requirements in the air-traffic control activity, as factors that add to the activity's complexity, needs to be understood and factored in the air-traffic control job design. Therefore, using the argumentations of Bedny and Karwowski (2007) and Sanda (2016) as point of departure, the level of required operational unpredictability in the air-traffic control activity, and the tacit knowledge used by the air-traffic controllers to override any performance uncertainty towards preserving air-traffic safety must be seen as an important mediating factor that enables air-traffic controllers' cope with the complexity of air-traffic control activity. 
This postulation is supported by Meister (1999) argument that a situation where an operator has to deal with more than three intermediate data on dynamic objects in memory should be subjectively evaluated as a very difficult situation which produces errors, while the duration for which information is kept in memory should also be considered a critical factor. The results have shown that the air-traffic control activity entails several air-controller-oriented motives (both conscious and unconscious) with varying priorities assigned to each influencing factor.

Arguing along the lines of Jarzabkowski (2003), air-traffic controllers could be viewed as having shared meanings of their local and situated organisational practices which could be understood by finding out how they systematically interpret unique circumstances in their work environment. Thus, in order to understand the full practice complement used by air-traffic controllers to sustain air-traffic safety while functioning under high levels of cognitive and workload demand salutations, their accompanying stresses, it is important to understand the situated and localised nature of tacit knowledge used to enhance such practices. The importance of such understanding is underscored by Bradley's (2002) observation to the effect that sometimes employees hide behind their computer screens (technology) to avoid conflicts or difficult meetings with other persons. This is because in the process of transforming a work practice, the workplace culture and identities is affected which in turn also challenges the old behaviours and attitudes of workers (Sanda et al., 2011). As it was highlighted by the result, air-traffic controllers use self-developed generic skills, such as, flexibility, technical intelligence, technical sensibility, perceptive ability, trustworthiness, independence, and sense of responsibility (Venda, 1975; Abrahamsson and Johansson, 2006) to cope with the cognitive and workload demand derived from the their operational activities and its associated uncertainties. Going by the arguments of Meister (1999), the uncertainty in the operators' air-traffic control activities is dependent on both the objective and subjective characteristics of the tasks. Arguing along the line of Meister (1999), the totality of these motives could be viewed as influencing the air-traffic controllers' emotions and motivations in the performance of the air-traffic control activities. Thus designers of the air-traffic control activity need to understand the emerging new mental images (tacit knowledge) of air-traffic controllers in order to be able to come out with human-oriented designs that can lend to the creation of a friendly, efficient and effective automated and digitised air-traffic control activity that can lend to the enhancement of air-traffic controllers management of air-traffic safety. In this respect, the model shown in Figure 5 can be used to uncover and understand the cognitive and emotional-motivational aspect of task complexity and the associated tacit knowledge of air-traffic controllers towards enhancing worker technology work environment design in air-traffic control activity.

By implication, the air-traffic control job environment must have good work and social conditions that can offset the stressfulness of the air-traffic control activity, and its associated emotional impact on air-traffic controllers' towards enhancing their motivational needs. This understanding will help designers of the air-traffic control activity and its associated tasks and operations, as well as the accompanying procedures for its performance, to optimise the activity's complexity by integrating the tacit knowledge used by the air-traffic controllers to cope with its cognitive and motivational-emotional challenges to ensure air-space safety management. 
Figure 5 Model for understanding air-traffic controllers' cognitive and mental workload and tacit knowledge for coping to ensure air-traffic safety

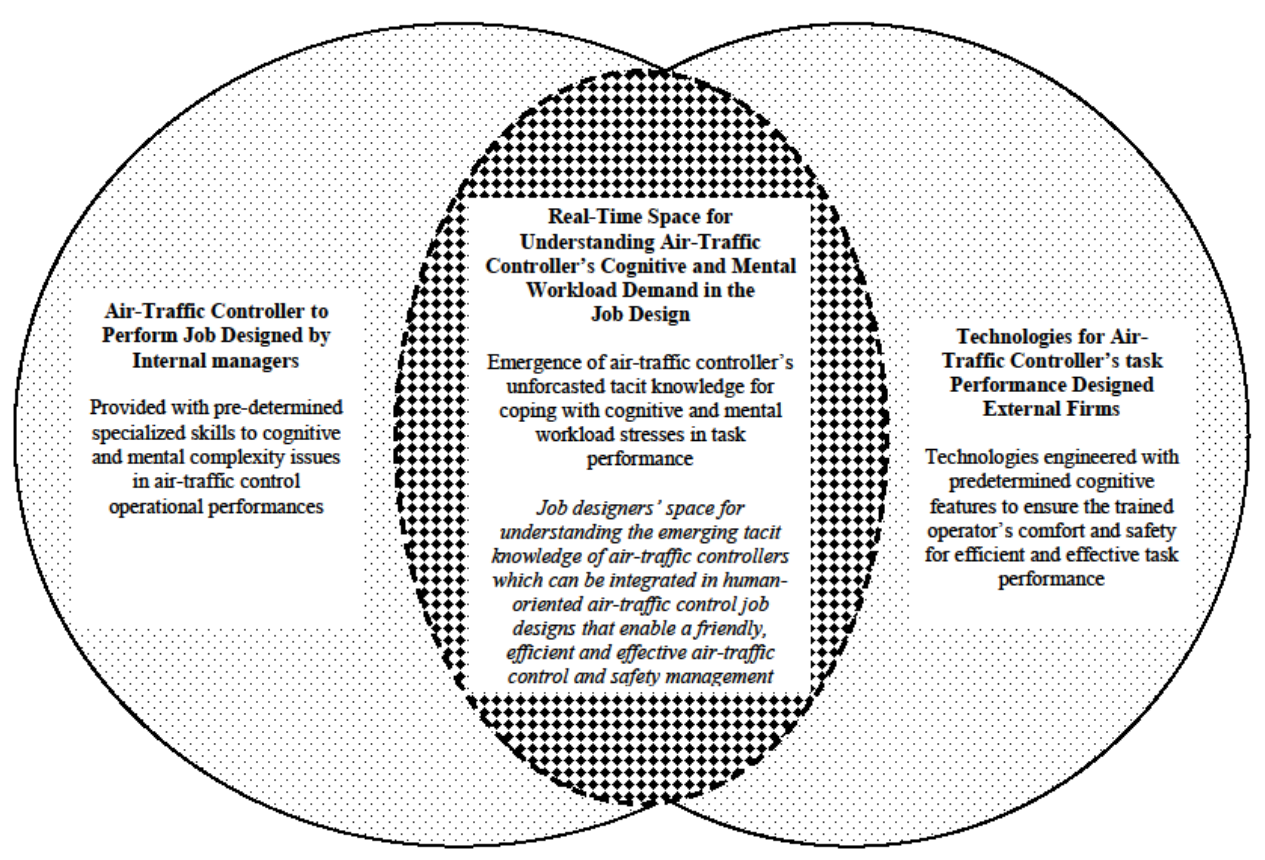

\section{Conclusions}

The study has shown that the air-traffic control entailed several operator-oriented challenges with the complexity of the activity as an influencing factor. Based on the findings as discussed above, it is obvious that a complex motor task in the air-traffic control activity can be performed by an air-traffic controller due to their trainings. Yet, the task undertaking demands significant cognitive effort and tacit knowledge input from the air-traffic controllers. Ameliorating the cognitive demanding processes of the air-traffic control activity is critical when the complexity associated with both the cognitive aspect and the emotional-motivational aspect of the tasks entailed in the activity is to be understood. This is because, as these complexities increase, the emotional tension and motivational force associated with the operators' work also increase. The tacit knowledge used by the air-traffic controllers to augment their operational performances and positively enhance air-traffic safety is stored in their memories, and thus represent a valuable human-oriented practice resource that can be captured, nurtured and used in various ways. Presumably, two or more air-traffic controllers can have similar tacit knowledge regarding a task, but may use different strategies in applying the knowledge in their work activities. Job designers of the task environment for the air-traffic control activity need to understand the emerging new mental images of the operators in order to be able to come out with human-oriented designs that can lend to the creation of a friendly, efficient and effective work environment for the air-traffic control. The work environment must also have good work and social conditions that can enhance the workers 'emotional-motivational orientation. It is therefore concluded that the functional 
efficiency and effectiveness of human work in the air-traffic control activity can be increased by understanding and integrating air-traffic controllers' tacit knowledge in the air-traffic control job design. By implication, air-traffic control job designers' understanding of the cognitive and workload demands felt by the air-traffic controllers can result in the design of operator-efficient and effective work system for that can significantly enhance air-traffic controllers' management of air-traffic safety in Ghana.

\section{References}

Abrahamsson, L. and Johansson, J. (2006) 'From grounded skills to sky qualifications: a study of workers creating and recreating qualifications, identity and gender at an underground iron ore mine in Sweden', Journal of Industrial Relations, Vol. 48 No. 5, pp.653-672.

Abrahamsson, L. and Johansson, J. (2008) 'Future mining: workers' skills, identity and gender when meeting changing technology', in Saydam, S. (Ed.): 1st International Future Mining Conference and Exhibition 2008, pp.19-21.

Acker, J. (2006) 'Gender and organizations', in Chafetz, J.S. (Ed.): Handbook of the Sociology of Gender, pp.177-194, Springer, New York.

Aldrich, H.E. (2008) Organisations and Environments, Stanford University Press, Stanford, California.

Ammennan, H.L., Bergen, L.J., Davies, D.K., Hostetler, C.M., Inman, E.E. and Jones, G.W. (1987) FAA Air Traffic Control Operations Concepts, AKTCC/HOST En Route Controllers, Report Number DOT/FAA/AP/86-01, Vol. 6, Washington, Federal Aviation Administration

Bedny, G.Z. and Karwowski, W. (2007) A Systemic-Structural Theory of Activity: Applications to Human Performance and Work Design, Taylor and Francis, Boca Raton, FL.

Blanken, S.M., Huisman, H. and Roerdink, M. (2010) 'The air traffic controller cognitive process and operational situation model: a model for analyzing cognitive complexity in ATM', Proceedings of 29th Conference of the European Association for Aviation Psychology, Budapest, Hungary.

Bourne Jr., L.E. and Yaroush, R. (2003) A Stress and Cognition: A Cognitive Psychological Perspective [online] http://www.psych.colorado.edu/ lbourne/StressCognition.pdf (accessed 15 August 2016).

Bradley, G. (2002) 'Information and communication technology (ICT) and changes in work life: macroergonomic considerations', in Hendrick, H.W. and Kleiner, B.M. (Eds.): Macroergonomics: Theory, Methods and Applications, pp.173-198, Lawrence Erlbaum, New Jersey.

Costa, G. (1996) Occupational Stress and Stress Prevention in Air Traffic Control, International Labour Office, Geneva.

Fenwick, T. (2006) 'Learning as grounding and flying: knowledge, skill and transformation in changing work contexts', Journal of Industrial Relations, Vol. 48, No. 5, pp.691-706.

Folkard, S. and Monk, T.H. (1991) Hours of Work: Temporal Factors in Work Scheduling, Wiley, Chichester.

Hendrick, H.W. and Kleiner, B.M. (2001) Macroergonomics: An Introduction to Work System Design, HFES, Santa Monica.

International Civil Aviation Organization (ICAO) (2002) Human Factors Guidelines for Safety Audits Manual (Doc 9806), ICAO, Montreal, Canada.

Jarzabkowski, P. (2003) 'Strategy as social practice: An activity theory perspective on continuity and change', Journal of Management Studies, Vol. 40, No. 1, pp.23-55.

Kieras, D. and Polson, P.G. (1985) 'An approach to the formal analysis of user complexity', International Journal of Man-Machine Studies, Vol. 22, No. 1, pp.365-394. 
Koros, A., Della Rocco, P.S., Panjwani, G., Ingurgio, V. and D’Arcy, J. (2003) Complexity in Air Traffic Control Towers: A Field Study [online] http://www.hf.tc.faa.gov/technotes/dot-faa-cttn03-14.pdf (accessed 17 August 2016).

Meister, D. (1999) The History of the Human Factors and Ergonomics, Lawrence Erlbaum Associates Publishers, Mahwah, NJ.

Mirabella, A. and Wheaton, G.R. (1974) Effects of Task Index Variations on Transfer of Training Criteria, Report NAVTRAEQUIPEN 72-C-0126-1, Naval Training Equipment Center, Orlando, Florida, January (AD 773-047/7GA).

Patton, M.Q. (1990) Qualitative Evaluation and Research Methods, Sage, Newbury Park, CA.

Pawlak, W.S., Brinton, C.R., Crouch, K. and Lancaster, K.M. (1996) 'A Framework for the evaluation of air traffic control complexity', American Institute of Aeronautics and Astronautics, Meeting Papers A9635735 [AIAA pp.96-3856], pp.1-11.

Sanda, M.A. (2010) 'Impact of value-based transformational leadership in privatizing government institutions in a developing economy: a case study', Business \& Management Quarterly, Review, Vol. 1, No. 3, pp.1-13.

Sanda, M.A. (2016) 'Cognitive and emotional-motivational implications', in The Job Design of Digitized Production Drilling in Deep Mines, in Hale, K.S. and Stanney, K.M. (Eds.): Advances in Neuroergonomics and Cognitive Engineering, Advances in Intelligent Systems and Computing, Vol. 488, pp.211-222, Springer, Switzerland.

Sanda, M.A., Johansson, J., Johansson, B. and Abrahamsson, L. (2011) 'Understanding social collaboration between actors and technology in an automated and digitized deep mining environment', Ergonomics, Vol. 54, No. 10, pp.904-916.

Sanda, M.A., Johansson, J., Johansson, B. and Abrahamsson, L. (2014) 'Using systemic structural activity approach in identifying strategies enhancing human performance in mining production drilling activity’, Theoretical Issues in Ergonomics Sciences, Vol. 15, No. 3, pp.262-282.

Smith, R.C. (1980) Stress, Anxiety and the Air Traffic Control Specialist, Federal Aviation Report, No. FAA-AM-80-14, Washington.

Venda, V.F. (1975) Engineering Psychology and Synthesis of Informational Sources, Manufacturing Publishers, Moscow.

Villena, J., Acevedo, J.M., Cruz, J.A. and Le Gal, S. (2008) 'Is it possible to observe air traffic controller (ATCOs) mental workload?', in Proceedings of 28th Conference of the European Association for Aviation Psychology, Valencia, Spain.

Wenger, E. (1998) Communities of Practice, Cambridge University Press, New York. 